\title{
Spleen Development
}

National Cancer Institute

\section{Source}

National Cancer Institute. Spleen Development. NCI Thesaurus. Code C19953.

Human Spleen Development involves formation of the spleen, initially as a long strip of cells adjacent to the forming stomach, from mesoderm in the dorsal mesogastrium. Initially an important organ for hematopoiesis (but lost with development), migration of lymphoid precursor cells into the spleen primordium leads to a gradual conversion of the spleen to an organ of the immune system. 